\title{
Entrevista com Hercules Gomes
}

André Repizo Marques ${ }^{1}$ Universidade Estadual Paulista Júlio de Mesquita Filho andre_repizo@hotmail.com 


\section{Apresentação}

No dia 17 de abril de 2017, às 14h, tive o privilégio de entrevistar o pianista brasileiro Hercules Gomes. Hercules Francisco Pinto Gomes (1980), pianista natural de Vitória (ES), estudou na Escola de Música do Espírito Santo (a então Emes) e se formou no curso de Música Popular da Universidade Estadual de Campinas (Unicamp). Ganhou o 11으 Prêmio Nabor Pires de Camargo - Instrumentista promovido pela Fundação Pró-Memória de Indaiatuba (2012). Em 2015, participou do projeto Gravação dos Concertos Cariocas de Radamés Gnattali, no qual interpretou o Concerto Carioca no 2 com a Orquestra Sinfônica de Campinas.

O primeiro contato com Hercules Gomes, via e-mail, foi para apresentar minha pesquisa e convidá-lo para uma entrevista acerca da interpretação ao piano, sobretudo da obra de Ernesto Nazareth. O pianista gravou a música Odeon, do referido compositor, no seu trabalho solo, o CD Pianismo (2013), nele podemos observar suas influências de ritmos brasileiros, jazz e de música erudita. Após alguns e-mails, marcamos a entrevista na residência do pianista. Segue a transcrição.

ARM: Fale sobre sua formação como pianista.

HG: Eu comecei muito diferente da maioria dos pianistas. Meu pai toca violão (como autodidata) e começou me ensinando os acordes no violão. Havia uns grupos e eles ensaiavam de vez em quando e, um dia, um amigo dele me deixou um tecladinho desses de tecla pequena, sabe? Da Casio, de quatro oitavas. Eu peguei o teclado e comecei a pegar aqueles acordes e passar para o teclado, tirar umas melodias, brincando mesmo. O primeiro contato com o instrumento de tecla foi esse, como autodidata. Meu pai tocava em uma igreja católica na época, aonde ele me levou depois para tocar também. Eu considero que isso foi muito importante, primeiro por desenvolver essa percepção auditiva e, depois, pela teoria. Eu tinha, nessa época, uns 13 para 14 anos. Eu comecei assim, tocando de ouvido mesmo. Tudo errado. Com 16 anos já tocava em bandas. A primeira banda foi de pagode. Toquei pagode, sertanejo, sou um cara que já tocou de tudo que você pode imaginar. Toquei desde Molejo, na época, Raça Negra, até concertos para piano e orquestra. Extremos. Na época que comecei a tocar em bandas, senti a necessidade de melhorar a parte teórica. Eu sempre fui muito interessado naquilo que eu gosto. $\mathrm{Na}$ adolescência era videogame, lia revistas etc. Depois, o aeromodelismo, ia fundo também. O piano não era diferente, eu gostava muito e queria estudar. Então, entrei numa escola de música, o Conservatório de música de Vila Velha. Eu tinha 16, quase 17 anos. Fiquei pouco tempo lá, uns oito meses, no máximo. Foi o

\footnotetext{
1 André Repizo Marques - Pianista, Mestre em Música pelo Instituto de Artes da Unesp, com pesquisa em música popular urbana brasileira do início do Século XX, mais especificamente na interpretação do choro ao piano. É Bacharel em Música- habilitação em Piano pelo Instituto de Artes da Unesp, formado pelo Conservatório Dramático Musical Dr. Carlos Campos de Tatuí no Curso de Piano Erudito e pela Emesp no Curso de Piano Popular. Atuou como pianista da Orquestra Jovem Tom Jobim (2011) e da Banda Sinfônica Jovem do Estado de São Paulo (2010). Atualmente, é pianista da Freedom Big Band e do André Repizo Trio, onde desenvolve o trabalho como compositor.
} 
lugar onde tive o primeiro contato com piano acústico e com teoria mesmo, embora já tivesse folheado livros. Tive meu primeiro piano na faculdade, com 21 anos de idade. Depois, eu saí e comecei a fazer o cursinho pré-vestibular para prestar a Unicamp. Já estava decidido. Então, eu entrei no Conservatório Estadual do Espírito Santo, que hoje é a Faculdade de Música do Espírito Santo. Fiquei muito pouco também, uns dois meses, porque tinha acabado de passar no vestibular e fui embora para Campinas. Neste momento é que eu considero que começou o meu ensino formal. Em Campinas, eu considero que teve um divisor de águas, que foi da época que eu comecei a estudar música até entrar na Unicamp (um ano e meio de curso, quando eu conheci o Silvio Baroni, um professor de piano clássico com quem estudei). A partir disso, eu considero um divisor de águas. Até então, eu não tinha estudado piano erudito, não sabia o que era. Eu fui atrás de técnica, na verdade. Queria tocar mais rápido, mas descobri que não é só isso, pelo contrário, descobri um mundo que eu não sabia que existia. Já tinha ouvido falar em Bach, Chopin, mas não sabia. Infelizmente isso é uma realidade, a pessoa que começa a estudar só música popular fica com um olhar fechado, e aquela que começa a estudar só música clássica também. A música clássica já tem uma tradição maior, a popular, não, e as coisas não se misturam. Tem gente que fala que é tudo música, mas não é. É muito diferente. São conceitos de música muito diferentes, algumas coisas se aproximam, mas é tudo muito diferente. São mundos diferentes. As pessoas, os músicos, os comportamentos, as músicas são diferentes. Existe isso, infelizmente. Principalmente porque o músico popular não se liga tanto na música clássica. Quando eu comecei a estudar com Silvio foi muito especial, porque, além de conhecer esse mundo, ele tinha uma técnica muito efetiva. Técnica criada pelo Pietro Maranca, que foi professor da Unesp. Ele pegou o melhor da técnica de basicamente três pianistas: Michelangeli, Maria Curcio e do Peter, não me lembro do sobrenome dele, e, dessa forma, criou uma técnica própria. O Silvio foi o aluno que estudou 12 anos com o Pietro Maranca, o aluno que mais absorveu essa técnica. A grande diferença dessa técnica para as demais que se aprende ao piano é que ela se baseia mais em articulação e leveza do que em peso, enfim, é totalmente diferente. Nela, cada dedo tem a sua articulação, o seu ângulo para tocar, tudo milimetricamente medido. Funciona para qualquer pianista. Não é algo que funciona melhor para um pianista e não para o outro, qualquer pianista pode tocar piano bem se dominar esse tipo de técnica. Não que seja fácil, tem que estudar muito até incorporar. Eu demorei bastante tempo e considero, hoje, a cada aula que faço com ele, que não sei nada, mas eu percebo que funciona muito bem e na época não foi diferente. Como eu nunca tinha estudado piano clássico, foi de certa forma mais rápido para mim, porque eu não tinha tantos vícios como os meus amigos que estudaram piano clássico desde os seis anos de idade. Isso foi fundamental, pois, além de conhecer uma música que eu não sabia que existia, pude conhecer movimentos de mão que não sabia que eram possíveis até então. Eu descobri o piano em si e comecei a estudá-lo: a sonoridade, a técnica e esse mundo de composições que existia também. Depois disso, eu não consegui mais tocar piano do mesmo jeito, música popular do mesmo jeito, e foi aí que comecei esse trabalho que tenho hoje. Então, o ensino formal eu considero que foram 
essas aulas que eu tive antes de entrar na Unicamp, mas foi basicamente a partir da Unicamp que eu comecei a ter o ensino formal. Depois que eu me formei e quando venci o prêmio Nabor foi muito importante, porque me deu um impulso, assim, comigo mesmo, sabe? Às vezes você precisa disso para começar a acreditar nas suas coisas, precisa que as pessoas falem "isso aí é legal!". Foi isso o que aconteceu. Então, decidi gravar meu disco. Essa coisa de carreira, apesar de ter tido vários grupos de música instrumental, ter participado de vários discos de outros amigos, começou a partir desse disco em 2013. Só consigo tocar desse jeito hoje porque eu conheci o Silvio nessa época e sempre gostei muito de música brasileira. O que acabei fazendo foi juntar um pouco das duas coisas para fazer o que faço hoje.

\section{ARM: Fale sobre seu aprendizado de música brasileira ao piano.}

HG: A música brasileira é o seguinte: querendo ou não, por nascermos no Brasil, crescemos ouvindo, de uma forma ou de outra, quando a gente estuda música, principalmente. Não tem ninguém que nunca tenha ouvido Odeon. A primeira vez que eu ouvi Nazareth foi com a Eudóxia de Barros, inclusive falei isso para ela. Um dia eu toquei na Sociedade Brasileira de Eubiose e ela foi ver, e então falei "Eudóxia, você é muito importante para mim, porque você foi o primeiro contato que tive com o choro". Foi o disco dela tocando Nazareth e um LP que eu tinha que se chamava Chorinhos e Chorões, que tinha Brasileirinho, Saxofone por que choras? etc. Desde a minha adolescência, já me identificava muito com aquela sonoridade, porém não sabia ler partitura, não tinha aula de piano. Então, o que eu fazia era tocar de ouvido. Na época não tinha entrado no conservatório ainda. Eu pegava o Odeon da Eudóxia de Barros e ficava tentando tirar lá no meu tecladinho. Foi esse o meu primeiro contato com música brasileira. Depois que eu entrei na faculdade, a coisa se expandiu um pouco mais, porque o mais legal da faculdade não é o que se aprende lá, mas, sim, o ambiente. Você está com pessoas que se interessam pela mesma coisa que você, que te apresentam coisas novas, e você também apresenta coisas novas para essas pessoas, e isso é muito interessante. Então, o meu primeiro contato com a música brasileira foi, principalmente, na faculdade e em alguns festivais, por exemplo, o Festival de Campos do Jordão. Vou tocar lá este ano, depois de 17 anos, fui para lá no ano 2000. O Festival Brasil Instrumental de Tatuí foi muito importante, em que estive em workshops com Trio Curupira, André Marques, Hermeto Pascoal. Isso foi muito importante para despertar o interesse na música brasileira, principalmente a mais tradicional. $O$ choro ainda é uma coisa restrita, pequena, mas que sobrevive há séculos e está bem. Porém, se falarmos de maracatu, frevo, caboclinho, por exemplo, para um estudante de música, é uma coisa que praticamente não existe, entende? E é música brasileira. É essa música brasileira que eu mais me identifico: o choro, o frevo, o maracatu, o samba. É essa música brasileira mais tradicional que eu tento trazer para o piano. E esse contato foi graças à época da faculdade, em que tive a oportunidade de assistir vários workshops em vários festivais e de perceber o que dá para fazer com isso. O que o André Marques fazia com o baião, com o choro, que é 
totalmente diferente do que o Luiz Gonzaga fazia. O Luiz Gonzaga criou aquilo, não é? Então, o instrumentista moderno pegou aquilo e transformou em outra coisa, e eu ficava tão impressionado que comecei a me interessar mais e mais por música brasileira, dessa tradicional.

ARM: No livro de Henrique Cazes (Choro: do quintal ao municipal. São Paulo: Ed. 34, 1998), há uma citação de Pixinguinha em que ele dizia que choro não se toca como está escrito. Nesse sentido, suas interpretações, como você já mencionou que são transcrições, mas no caso dos discos de Jacob do Bandolim, por exemplo, são interpretações sobre temas de Nazareth. No caso do disco Os Pianeiros, a música Odeon consta com arranjo de Carolina Cardoso de Menezes. Como você entende essa questão? Arranjo, interpretação, transcrição etc.

HG: A transcrição, no meu caso, eu mudo tudo mesmo. Pois é, o Jacob também mudava tudo, até a tonalidade da música. Na verdade, são formas diferentes de se falar a mesma coisa. Tem a questão da música escrita e a da música improvisada. Tem gente que diz que o melhor não é chamar música erudita e popular, e sim escrita e improvisada. Eu considero essa afirmação de Pixinguinha muito boa, porque a música escrita você não vai tocar do jeito que está escrito. Acho que nada é tocado do jeito que está escrito, nem Mozart. Choro, que é ainda mais complexo no sentido de articulação, talvez não mais complexo, mais novo e menos estudado. Mozart, você vai tocar aquelas notas, mas não é que você vai tocar o que está escrito, vai colocar sua interpretação naquelas notas, então, é escrita nesse sentido. A música improvisada não é aquela que você vai tocar um tema e sair improvisando, e sim a que você tem a liberdade de colocar a sua personalidade, alterando a forma, a harmonia, a nota, fazendo do seu jeito. Então, estes dois conceitos, eu acho ótimos. E a questão da transcrição, no meu caso, é você pegar uma música que foi escrita de uma forma... [silêncio] É assim: se você pegar uma música que foi escrita para piano e tocar no bandolim, terá que fazer uma adaptação, uma transcrição, um arranjo, não tem jeito. Agora, se você pegar uma música que foi escrita para piano e tocar de outra forma, dependendo da forma que ficar, eu prefiro chamar de transcrição do que de arranjo, porque o arranjo tende para a "coisa do popular", que é mais simples, mas, se você fala em transcrição, entraria em um conceito mais técnico, mais clássico. Enfim, no fim das contas, é a mesma coisa. Às vezes, a gente tenta achar justificativa, denominar, e não chega a lugar nenhum. O Jacob, poderíamos chamar mais de arranjo do que de transcrição. Acho que depende do estilo, não é? Eu queria fazer um negócio mais no estilo do Horowitz mesmo, para tocar em sala de concerto, não para tocar em bar, que tenha uma terminologia de música clássica.

ARM: As partituras da obra de Nazareth que temos editadas fornecem todas as informações necessárias?

HG: Essa é uma coisa curiosa. Aquilo que você disse do choro, que o Henrique Cazes fala, não é só choro, mas qualquer tipo de música. Não é exatamente o que está 
escrito, nunca é, mas o choro tem um negócio que, para você entender, você tem que ouvir choro, tocar choro. São umas coisas de articulação. Se eu tocar Ernesto Nazareth, do jeito que ele escreveu, vai sair muito diferente da Sônia Rubinsky, da Eudóxia de Barros, da Maria Tereza Madeira. Talvez, fique mais próximo do jeito que o Radamés tocava do que do jeito que elas tocam, porque o choro tem essas duas formas. O Ernesto Nazareth, a gente pode chamar de choro, porque tem todas as características de choro, mas ao mesmo tempo dá para chamar de música de concerto. É o que ele queria que fosse, não é? O jeito que os pianistas clássicos tocam, geralmente com mais rubato, se alarga mais, de uma forma mais lírica, dessa forma pende mais para a música de concerto. Agora, o jeito que o Radamés tocava pende mais para o choro. Não estou falando das valsas, estou falando dos choros mesmo: Brejeiro, Odeon, Fon-Fon. Um pianista clássico vai tocar mais rubato, já o popular com mais malemolência, mais ginga. A música do Ernesto Nazareth tem essas duas coisas. Eu gosto mais do lado do choro, porque eu gosto muito de choro. Eu enxergo muito balanço na música dele, mas acredito que tem essas duas leituras. É uma coisa curiosa isso. A música dele aceita muitas interpretações. Se pensarmos em música de concerto, as partituras editadas dele trazem todas as informações, sim. Se pegarmos um pianista russo para tocar, ele vai tocar muito bem, vai sair bonito, só que não vai ter ginga nenhuma. Ele vai tocar como ele toca Chopin. Para falar a verdade, eu acredito que o Ernesto Nazareth ia gostar mais do que se ele me ouvisse tocando [risos], porque ele queria que a música dele soasse mais desse jeito, entende? As edições trazem o essencial para tocar da forma europeia, agora, para tocar da forma brasileira, como choro, eu acho que deveria ser escrito de outro jeito. Nem sei se tem um jeito de escrever que faça você tocar dessa forma que eu penso, sabe? Quando eu escrevo minhas partituras, tento chegar do jeito mais próximo, mas, mesmo assim, a partitura parece um E.T. Se der para um pianista tocar, ele vai tocar de outro jeito. É difícil de colocar no papel, porque essa outra forma de tocar está mais relacionada ao choro. Agora, se a gente falar dessa interpretação mais tradicional, que é essa dos palcos, da sala de concerto, eu acho que a partitura está de ótimo tamanho. Tanto que a música está aí até hoje por isso, não é?

ARM: Ao estudar uma música de Nazareth ou outro compositor semelhante, você faz análise harmônica, fraseológica e formal?

HG: Não. Às vezes, eu prefiro ouvir uma gravação, como a Sônia Rubinsky tocando, e tirar de ouvido as harmonias do que pegar a partitura do Ernesto Nazareth e ficar vendo. Ah! Aqui é um Dó maior, um Dó sustenido menor com sétima etc. Para mim, é mais rápido e soa mais orgânico. Ou, às vezes, eu prefiro pegar um regional de choro tocando Nazareth do que um pianista clássico tocando Nazareth. Ou, às vezes, uma partitura com melodia e cifra é perfeito para mim, porque você tem o resumo do que é a obra. Eu fico com muito mais liberdade para criar do que se pegasse a partitura do Ernesto Nazareth e lesse. 


\section{ARM: Então o seu primeiro contato é com o áudio?}

HG: O primeiro contato é com o áudio. Se eu vivesse no século XIX, já não seria um bom pianista, pois não tinha áudio. Como nós somos de uma geração com tecnologia, temos que aproveitar. Eu economizo muito tempo assim, porque a minha leitura à primeira vista não é das melhores. Por isso, eu acho a gravação muito importante, como a Maria Tereza Madeira fez a gravação integral de Nazareth. Dessa forma, você desperta o interesse das pessoas para tocarem aquilo com uma velocidade maior, porque até o sujeito pegar todas as partituras e ler... Ninguém faz isso. Tem muita coisa do Ernesto Nazareth que ninguém conheceria se não tivesse gravado, e se outros pianistas não tivessem gravado também. Meu primeiro contato sempre é com gravação. A não ser que não tenha, como, por exemplo, umas músicas do Aurélio Cavalcanti que estava tocando, não tem gravação, apenas a partitura. Então eu peguei a partitura e comecei a ler, e o pior é que é bom. O Odeon não foi diferente, foi com gravação o meu primeiro contato.

ARM: As músicas de Nazareth são tangos, maxixes etc. Você pensa na origem dessas danças, tocando como se fosse para dançar?

HG: Eu penso mais em música instrumental, embora eu goste muito dessa coisa para dançar também. Antigamente tinha isso, os pianistas tocavam muito em baile. Se você escuta o Nonô tocando, o próprio Ernesto Nazareth, o Artur Camilo, que acompanhava o Patápio e um monte de gente, tinha uma coisa de pegada ali que você percebe que o pianista estava "sentando a mão", não é? Mas por quê? Porque precisava. Era um piano acústico e um baile para animar. Às vezes, até para gravar tinha que tocar muito forte para ferir o acetato, o disco antes do vinil. Por que as primeiras gravações são de bandas? Porque as bandas tinham uma potência muito grande e então era possível gravar isso, já o piano, não. O piano também tem potência, mas tem que tocar forte. Se tocasse fraco, o som ficava pequeno naquela época. Então, dá para perceber que os pianistas tocavam forte, era com "pegada". Já ouviu Uma Farra em Campo Grande? Uma gravação do Nonô, que é um bom exemplo disso. Dá para perceber que ele estava tocando forte porque precisava tocar assim para gravar no disco, e ele estava acostumado a fazer assim ao animar os bailes. Eu me "amarro" nisso! Da bossa nova para cá, os pianistas começaram a tocar muito como os jazzistas, porque a música brasileira começou a receber muita influência do jazz, então, ficou uma coisa muito mais tranquila e se perdeu um pouco disso, dessa "pegada" de samba de choro.

ARM: O músico popular tem uma maneira de tocar que é semelhante à do arranjador. No caso do choro, e mais especificamente em Nazareth, observamos interpretações bem distintas. Como você enxerga esse cenário?

HG: Eu acho que todos têm essa veia de chorão mesmo ao tocar. Você encontra gravações de todos eles tocando normal, sem inventar muito, um tema com acompanhamento. Mas, ao mesmo tempo, tem alguns que vão muito além. O Radamés, eu acho 
que é uma exceção nesse sentido, não é? Tudo do Radamés tinha muitas vozes, gostava muito de Bach, muito contraponto, era tudo muito elaborado. Diz o Laércio de Freitas que ele não improvisava nada, tocava com a partitura na frente. Mesmo em alguns solos que tem nas músicas dele. Por exemplo, quando você toca Zanzando em Copacabana, o segundo C parece um improviso, mas não é, é tudo escrito. Você toca o Remexendo, que tem várias versões, há uns solos que parecem improvisos, umas frases até meio jazzísticas, mas não é, está tudo escrito. É um músico que, ao mesmo tempo que compôs choros, compôs músicas de concerto, sinfonias, concerto para piano, concerto para harpa, e, ao mesmo tempo, ele tem uma coisa que fica ali no meio-termo. Não é que fica em cima do muro, não, é que são as duas coisas muito bem-feitas, com propriedade. É a mistura do popular com o erudito de uma forma excepcional. Eu mesmo gravei o Concerto Carioca e, tocando isso, você percebe que realmente ele sabia muito bem das duas coisas. Não era um clássico tentando, como acontece com muitos compositores: o clássico que tenta tocar o jazz, o choro, e fica aquele negócio muito forçado, não é? E, às vezes, o contrário, o popular tenta trazer umas influências do clássico, e aí fica muito brega, exagerado demais. Radamés era um músico que tinha esse negócio na medida certa. Eu acho que por isso ele foi tão genial. Agora, no piano ele tem as duas coisas também. Eu já vi o Radamés tocando coisas simples, acompanhando. Odeon ele tocava de uma forma simples, mas sempre colocava uma coisa dele que era nova e mais complicada. E já vi tocando coisas que era para ser simples, e ele coloca um monte de vozes, um monte de coisas. O Nazareth já é outra época, Radamés é uma geração para lá do Nazareth, mas, nessa época do Nazareth, os pianistas compunham mesmo como a gente enxerga hoje a música clássica, a música erudita. Era tudo escrito, é isso que quero dizer. Já na época do Radamés, já tinha essa veia da música popular mesmo, mais improvisada, já bebeu mais nessa fonte do choro. Você pega pianistas como Tia Amélia, por exemplo, você entende uma valsa, um choro rápido e um choro lento, mais seresteiro, você entende todas as músicas, porque é tudo igual. Então, o estilo dela é muito simples, mas swinga tanto, com uma personalidade tão grande, que você ouve uma gravação dela e logo identifica: é Tia Amélia. Não dá para entender como pode ser uma pianista que está esquecida hoje em dia. Já o Maestro Gaó, por exemplo, é um músico que tocava muito bem piano, mas tinha também essa veia de arranjador, escrevia para orquestra etc. Então, alguns arranjos já transcendiam um pouco disso, mas ao mesmo tempo ele compunha como Nazareth. Tem a música Teimoso, do Gaó, que é um estudo de sextas maravilhoso, supertécnico. Um músico que tocava muito. Mas eu acho que todos têm um pouco disso, um pouco do chorão e um pouco de trazer outras influências para o piano, mas alguns vão além. Já o André Mehmari, no disco Ouro sobre o azul, com as músicas de Nazareth, eu acho fantástico, mas já é um músico da nossa geração. Antes dele, já teve outra geração, que é a geração do piano da bossa nova, como Amilton Godoy, Cesar Camargo Mariano. Um pouco depois disso, surgiram os pianistas que são dessa nova onda, mais moderna, como Egberto Gismonti e Hermeto Pascoal. Eu enxergo que tem essas diferenças, porque eu sempre tive uma pergunta comigo. A gente sempre ouve falar desses músicos da bossa nova, do Dick Farney para 
cá, e do Ernesto Nazareth, da Chiquinha Gonzaga, desses músicos lá atrás. E no meio disso aí, não é? O que aconteceu? Eu não sabia. Não tinha registro disso. Curioso, que um dia eu dei aula na Oficina de Curitiba e encontrei o Rodrigo Y. Castro, flautista que tenho um duo hoje. Ele me falou "Você vai dar aula de piano popular, vai falar de choro? Então, deve conhecer os Pianeiros, Tia Amélia, Carolina Cardozo de Menezes, Maestro Gaó, Radamés etc.". Eu lembro que, da lista de dez que ele falou, eu conhecia dois. Eu falei: o que é isso? Eu preciso ir atrás. E dessa forma eu encontrei a resposta para isso. Onde estava esse elo perdido do piano brasileiro, 50 anos entre Ernesto Nazareth e Dick Farney? Está exatamente na Tia Amélia, no Radamés, no Maestro Gaó, na Carolina Cardozo de Menezes e em tantos pianistas que deixaram gravações. Mas elas não foram relançadas em CD, a maioria delas. Também não deixaram tantas partituras, porque já são pianistas da era da gravação. Por que Ernesto Nazareth está aí? Por que Mozart está aí? Porque não existia gravação. Para lançar uma música, tinha que lançar a partitura. Como a música é muito boa, ela está aí até hoje. Por isso os músicos tocam. Agora, com a era da gravação, muita coisa foi gravada e não foi escrita, ou foi escrita e se perdeu. Porque, se você tem o disco para ouvir, não precisa mais da partitura para tocar em casa. Por isso muita coisa se perdeu, muita coisa não foi relançada e as partituras são raras, como Tia Amélia e Carolina, por exemplo. Carolina era compositora também. Tem muitos temas bons. Nesse sentido, eu acho que por isso se criou esse elo na música popular brasileira (isso é história do Brasil, 50 anos que ninguém ouvia falar até então), por causa de pesquisas como esta que hoje em dia se ouve falar. Muita gente começou a pesquisar sobre Nazareth, a gravar Nazareth, Chiquinha, que teve o seriado da Rede Globo. Tem muitas teses sobre os Pianeiros, e algumas sobre alguns dos Pianeiros. A Maria Tereza Madeira tem uma tese sobre a Carolina e também gravou um disco só com composições da Carolina, mas ela não lançou ainda e nem sei se vai lançar. O Roberval Linhares Rosa lançou aquele livro sobre os Pianeiros, fantástico. Por causa dessas iniciativas, a coisa está começando a renascer, e precisa, porque é um material muito rico para se explorar. Agora, o Mehmari é ótimo. Ele é um músico que eu acompanho desde a minha adolescência. É um músico incrível, eu não sei como em uma encarnação uma pessoa consegue fazer tanta coisa, porque ele transcende o piano, ele não é só pianista. Ele é arranjador, compositor, faz trilha, toca outros instrumentos. Não sei como dá tempo. Eu estudo piano o dia inteiro e não consigo tocar direito. No disco que ele toca Nazareth, é um outro caminho, já não é o caminho do Pianeiro, embora tenha compassos que swingam bastante (quando ele quer, ele swinga), mas não é a praia dele. Ele é um músico que pensa de outra forma. O Radamés também era um pouco assim, mas pendia mais para o choro mesmo. O Mehmari pensa no arranjo como uma coisa orquestral, não é um arranjo que vai começar em um andamento, $110 \mathrm{bpm}$, por exemplo, e vai até o final no mesmo andamento, com A A B C; não, ele começa com aquele tema e harmonia e vai embora, com rubatos, enfim, com accel., rearmonizações, com citações de outros compositores e de outras músicas. Isso que é interessante: já imaginou se todo mundo tocasse igual ao Nazareth ou Radamés? Não teria graça nenhuma. O mais incrivel é que a obra do Nazareth permite isso. Não é com qualquer compositor que se consegue isso. 
A obra dele é muito boa. As músicas são muito boas. Eu já ouvi Nazareth desde piano solo, regional de choro até bandas de rock, e fica bom. Como é que explica isso, não é? Muito bom.

ARM: Comente este trecho: "Um problema à parte é a falta de jeito dos pianistas brasileiros para tocar Nazareth. Se ouvimos suas obras executadas pelos chamados pianistas (como a suingadíssima Carolina Cardoso de Menezes), fica faltando um toque de sofisticação. Se as ouvimos tocadas por pianistas clássicos, muitas vezes de sólida reputação no meio erudito, falta o balanço" (CAZES, 1998, p. 36).

HG: Exatamente. É isso mesmo. Ele definiu tudo. Eu adoro esse livro. Isso é porque, geralmente, o pianista popular não tem a vivência e a técnica que o pianista de música clássica tem. A pesquisa do pianista clássico de sonoridade, estética, o popular não tem. Tem muita coisa na música popular deixada de lado, e o pianista clássico tem a técnica, mas geralmente não tem a vivência, o balanço que o pianista popular acaba tendo. É difícil encontrar as duas coisas. Acho que o Henrique fala do Radamés nesse trecho do livro. Ele era um músico que tinha bem as duas coisas, ele tocava a Sonata em Si menor de Liszt, era um baita pianista. Você tocando as coisas dele, [silêncio] não sei se você já tocou. Vale a pena. É muito legal. Principalmente as músicas que são mais choros, o Canhoto, o Capueirando. É uma delícia tocar. Difícil! E é uma escrita traiçoeira, sabe? Como Bach, se você errar uma nota, acaba indo para outro lado e dançou. Também é uma escrita muito sofisticada. Eu adoro, sou apaixonado por Radamés. Ele era um grande compositor e, como pianista, tinha as duas coisas, a técnica e o balanço. É muito difícil de encontrar isso.

ARM: Ao lermos a bibliografia acerca da obra de Ernesto Nazareth, encontramos afirmações como a do pesquisador Mozart Araújo (apud SALLES, Vicente. Rapsódia Brasileira. Fortaleza: Universidade Estadual do Ceará, 1994. p. 88): "Nazareth fez de seu piano uma espécie de síntese da música dos chorões"; e do Henrique Cazes (1998, p. 36): "Nazareth traduziu a música dos chorões para o piano". Comente essas afirmações.

HG: Eu concordo. Em minhas conclusões, dos livros que li, que não são muitos, na época não existia gravação, então, o piano tinha um papel meio que social de levar a música para dentro da casa das pessoas, tanto é que elas compravam partituras. Nazareth era demonstrador, não é? A pessoa queria comprar aquela música para ouvir em casa, tinha que ter o piano em casa e alguém que tocasse piano. Se a pessoa não lia bem, o demonstrador tocava e então a pessoa comprava e levava. Então, nas composições de Nazareth... [silêncio] Ele ouvia choro, era a música da época. Ainda é difícil de pensar isso hoje. A música que tocava no rádio, equivalente a tocar na televisão hoje, era a linguagem do choro. Difícil pensar isso hoje, mas era o que era. Ele pegava essa música e trazia para o piano. Então, eu acho que ele foi um músico fundamental nesse sentido. Não só ele, a gente fala muito no Ernesto Nazareth, que ficou muito conheci- 
do, e na Chiquinha Gonzaga, mas o Aurélio Cavalcanti, que compunha muito parecido com Ernesto Nazareth, porque é da mesma época, tem mais músicas do que o Ernesto Nazareth. Cavalcanti tem composições belíssimas também. Acho que não só o Ernesto Nazareth, mas todos esses fizeram isso, traduziam a música da rua para o piano. Mas, como eles tinham uma bagagem de música clássica (Nazareth não estudou tanto, mas de certa forma ele tinha uma bagagem de música clássica), acabavam fazendo isso para o piano com certa sofisticação. Eu acredito, sim, nessa tese.

ARM: Você pensa na instrumentação do choro quando toca? Em fazer um baixo do violão, uma célula rítmica do cavaco?

HG: Eu penso sempre. Eu penso em outros instrumentos, porque eu gosto muito de tocar solo, tenho um trio, um duo, mas gosto muito dessa coisa de levada, de acompanhamento. Uma vez estava conversando com o Laércio de Freitas, que para mim é a evolução, o último Pianeiro, uma herança direta de Nazareth, Radamés e Laércio. Para mim, segue a linha do tempo. Veja bem, Radamés conheceu Ernesto Nazareth, aprendeu com ele ouvindo, tocando as músicas dele. O Laércio conviveu dez anos com Radamés, conheceu o Radamés, você percebe? É uma herança direta. O Laércio é um músico que foi além, porque ele é mais novo, ele viveu coisas que o Radamés não viu. Ele incorporou bem essa linguagem do choro no piano. Eu ouvia o Laércio tocando e falava "de onde ele tira essas levadas?". Não dá para tirar de ouvido. Então me encontrei com ele um dia e perguntei "de onde você tira isso?". Ele virou para mim e disse: "Nem sempre a resposta está em seu instrumento". E é verdade, porque uma coisa que não foi criada no instrumento ainda não dá para inventar sozinho, você tem que buscar na fonte, não é? Então, onde ele busca? No regional de choro. A levada de cavaquinho, ele busca ouvindo cavaquinho, não é ouvindo outro pianista, porque outro pianista não fez essa levada de cavaquinho ainda, ninguém fez. O Radamés tinha feito algumas coisas. É uma coisa que eu acabo pensando muito, nos outros instrumentos. Eu gosto de tocar uma música e mudar tudo sem perder a essência da música. O que é? É uma valsa? Então vai ser valsa para sempre. É um choro? Então, no meu arranjo vai ser choro, porém vou fazer uma transcrição para o piano, não tem jeito. Mas eu penso em outros instrumentos, sim. Se estiver fazendo uma linha de baixo, eu quero que soe igual o violão, porque, se soar igual ao piano, muita gente já fez, mas, se pegar a referência de outros instrumentos, irá soar uma coisa nova. Já que o assunto é Odeon, nele eu pensei em outros instrumentos. A subida na melodia do A eu tirei do Radamés em um vídeo do YouTube em que ele toca para o Tom Jobim [Hercules toca o trecho do compasso 5962 do arranjo]. As "baixarias", eu pensei no violão de sete cordas [Hercules toca a mão esquerda do compasso 63 do arranjo]. Esse arranjo, eu não fiz com tanta consciência, eu tirei pouca coisa, porque eu nem conhecia os Pianeiros. O engraçado é que, depois, eu percebi que tem muita coisa que eu fiz que a Carolina fazia, que a Tia Amélia fazia. Por quê? Porque eu ouvi Cesar Camargo Mariano, e os pianistas que vieram bem depois e que também acabaram ouvindo e absorvendo esse tipo de coisa. Esses baixos [Hercu- 
les toca a mão esquerda do compasso 23 do arranjo, mais especificamente o segundo tempo], a Tia Amélia fazia direto. A Carolina também usava a mão direita mais swingada no A. Enfim, eu tirei uma coisa ou outra do Radamés e de regional de choro. Na época eu fiquei em dúvida, será que eu faço em Dó sustenido menor ou em Ré menor? Porque no choro eles tocam em Ré menor, geralmente, mas resolvi fazer no original mesmo.

ARM: Eu penso que talvez Nazareth escrevesse de forma simplificada com o objetivo de vender as músicas, porém não encontrei embasamento teórico para essa linha de raciocínio.

HG: Eu tenho para mim que ele não economizava muito, não. Eu sinto o Zequinha de Abreu muito econômico, mas acho que é por uma limitação dele mesmo, Chiquinha, às vezes. O Nazareth é bem refinado, pode ser que uma música ou outra seja simples, mas, no geral, escrevia bem. Não dá para comparar a complexidade com Chopin, porque é outra coisa, mas, desses Pianeiros, o Nazareth é o mais sofisticado e refinado, tirando o Radamés e os músicos mais novos.

ARM: Continuamos conversando, até nos despedirmos.

A presente entrevista contribuiu imensamente para minha pesquisa acadêmica de mestrado (concluída dia 26 de junho de 2017), que tem por propósito investigar a diversidade de interpretações da obra de Ernesto Nazareth, cuja performance tem sido realizada tanto por pianistas eruditos como por rodas de choro. Desta forma, tive a oportunidade de ter a contribuição do pianista Hercules Gomes, onde deixa claro que em sua gravação houve a intenção de fazer um arranjo, pois, para o pianista, interpretar é tocar exatamente o que Nazareth escreveu. Com certeza, essa entrevista foi uma aula inesquecível. 